\title{
Produção de bovinos de corte e leite em sistema de integração lavoura-pecuária
}

\author{
Production of beef and dairy cattle in integrated crop-livestock systems
}

\author{
Maxwelder Santos Soares ${ }^{1 *}$, Poliana Batista Aguilar², Franklin Meireles de Oliveira ${ }^{3}$, Leonardo Guimarães Silva ${ }^{1}$, \\ Wendell Fernando Guimarães da $\mathrm{Cruz}^{4}$ \\ ${ }^{1}$ Universidade Estadual Paulista (UNESP), Jaboticabal, SP, Brasil \\ 2 Universidade Estadual do Sudoeste da Bahia (UESB), Itapetinga, BA, Brasil \\ 3 Universidade Estadual de Montes Claros (Unimontes), Montes Claros, MG, Brasil \\ ${ }^{4}$ Universidade Federal de Lavras (UFLA), Lavras, MG, Brasil
}

\section{Resumo}

Objetivou-se analisar a integração lavoura-pecuária e a utilização deste sistema na produção de bovinos de corte e de leite. A integração lavoura-pecuária é uma alternativa que está sendo adotada entre os elementos tecnológicos disponíveis, destacando-se por apresentar um sinergismo entre a produção de culturas anuais e a produção de forragem para exploração da pecuária de corte ou de leite, a pasto. 0 sistema de integração lavoura-pecuária tem potencial para aumentar a produtividade de grãos, carne ou leite e reduzir os efeitos da degradação das pastagens de forma sustentável. No entanto, para o adequado funcionamento, alguns fundamentos devem ser atendidos, além da sincronização correta do uso dos principais componentes do sistema: o solo, a planta e o animal.

Palavras-chave: Culturas. Forragem. Produtividade.

\section{Abstract}

The aim of this study was to analyze crop-livestock integration and its use in beefand dairy cattle production. The crop-livestock integration is an alternative system that is being adopted among the available technological practices, being highlighted by the synergy between the production of annual crops and fodder for beef and dairy cattle under grazing. The crop-livestock integration system has the potential to increase the productivity of grains, meat or milk and to reduce the effects of pasture degradation in a sustainable way. However, some fundamentals must be met to obtain satisfactory results, in addition to the correct synchronization of the use of the main components of the system: soil, plant, and animal.

Keywords: Crop. Forage. Productivity. 


\section{Introdução}

A pecuária brasileira caracteriza-se pela grande dependência de pastagens, que são constituídas, principalmente, por forrageiras tropicais nativas e cultivadas, com produção sazonal em consequência de fatores climáticos (Agnes et al., 2004). Apesar de todas as dificuldades encontradas, tradicionalmente as pastagens tropicais são a principal fonte de alimento para produção animal no Brasil, sobretudo a de bovinos de corte e de leite (Gimenes et al., 2010).

O Brasil possui aproximadamente 180 milhões de hectares de pastagens nativas e cultivadas, dos quais mais da metade está em estágio de degradação, com boa parte já em estágio avançado (Embrapa, 2012). A degradação das pastagens pode ser considerada como um dos grandes problemas da pecuária brasileira, já que os sistemas de produção, em sua maioria, têm nas pastagens a sua base, tornando muito frágil a sustentabilidade do sistema (Pereira, 2004). A recuperação das pastagens é fundamental para a sustentabilidade da pecuária bovina e pode ser feita de forma direta ou por meio de integração com lavoura (Embrapa, 2012).

A Integração Lavoura-Pecuária (ILP) é uma alternativa que está sendo adotada entre os elementos tecnológicos disponíveis, destacandose por apresentar um sinergismo entre a produção de culturas anuais e a produção de forragem para exploração da pecuária de corte ou de leite a pasto, além de apresentar vantagens agronômicas, sociais e ambientais (Cobucci et al., 2001).

A ILP visa produzir grãos e produtos animais com alta eficiência, permitindo aos rebanhos uma dieta de boa qualidade e em boa quantidade ao longo de todo o ano. Assim, possibilita a utilização de áreas antes não exploradas ou subaproveitadas, durante algum período do ano, para o cultivo de espécies forrageiras (Turini, 2009). 0 sucesso do sistema de ILP depende de diversos fatores que são dinâmicos e interagem entre si; dentre os componentes do sistema, os principais são o solo, a planta e o animal (Cassol, 2003).

Objetivou-se com esta revisão abordar a ILP e a utilização deste sistema na produção de bovinos de corte e de leite.

\section{Integração lavoura-pecuária}

O sistema de ILP teve início com o plantio direto da soja sobre pastagens perenes na fazenda Cabeceira, no município de Maracaju, Mato Grosso do Sul, no ano de 1989, com Ake Bernhard e Krijn Wielemarker, ambos produtores de soja e criadores de bovinos (Borges, 2004). Essa integração tornou-se uma opção vantajosa, beneficiando duas atividades de grande importância econômica, a produção de grãos e a pecuária, proporcionando ganhos aos produtores (Salton et al., 2001).

A ILP pode ser definida como um sistema de produção que alterna, na mesma área, o cultivo de culturas destinadas à produção vegetal, sobretudo grãos e pastagens anuais ou perenes, e à produção animal (Nascimento e Carvalho, 2011). Dentro desse conceito, as áreas de lavouras dão suporte à pecuária por meio da produção de alimento para o animal, seja na forma de grãos, silagem, feno ou pastejo direto, aumentando a capacidade de produção da propriedade, permitindo a venda de animais na entressafra e proporcionando melhor distribuição de receita durante o ano (Mello et al., 2004).

O sistema de ILP pode ser utilizado com sucesso em pequenas e em grandes propriedades rurais. No caso de grandes áreas, a produção animal geralmente é representada por bovinos de corte, e a produção vegetal é constituída por culturas altamente mecanizadas, como a soja, por exemplo. Já em propriedades que não dispõem de extensas áreas agrícolas, como é o caso da maioria dos estabelecimentos rurais do Brasil, a produção animal, em geral, é representada por bovinos destinados à produção de leite. Por sua vez, a produção vegetal é constituída por culturas como o fumo, o feijão e o milho, este último destinado à produção de silagem e grãos (Balbinot Jr et al., 2009).

Os objetivos da ILP são: diversificar culturas favorecendo a rotação; melhorar as condições físicas, químicas e biológicas do solo; recuperar a fertilidade do solo com a lavoura em áreas de pastagens degradadas; aumentar a eficiência de utilização de fertilizantes e corretivos; preservar o meio ambiente; produzir forragem para alimentação animal e para cobertura e manutenção do solo na estação seca do ano (Gimenes et al., 2010). 


\section{Fundamentos do sistema de integração lavoura-pecuária}

Embora o sistema de ILP possa apresentar vantagens em relação a sistemas não-integrados de produção que apresentam somente produção vegetal ou animal de forma isolada, o sucesso da ILP depende de adequado conhecimento sobre o sistema como um todo. 0 manejo da propriedade deve ser realizado com o objetivo de obtenção de elevados rendimentos, seja no componente vegetal como no animal. Sistemas que envolvem a interação solo-planta-animal são mais complexos do que sistemas que envolvem somente a interação solo-planta. Esse conhecimento deve servir de subsídio para o planejamento das ações a serem desenvolvidas nas propriedades (Balbinot Jr et al., 2009). O sistema de ILP pressupõe a prática de cinco fundamentos básicos:

- Correção da acidez e fertilidade do solo: a maioria dos solos do Brasil possui elevada acidez e concentrações baixas de fósforo (Abreu Jr et al., 2003). A correção da acidez do solo com uso de calcário, em doses recomendadas para elevar o $\mathrm{pH}$ do solo para a faixa de 5,5 a 6,0, bem como o aumento da concentração de fósforo, são práticas fundamentais para garantir alto rendimento da maioria das culturas destinadas à produção vegetal e das pastagens (Balbinot Jr et al., 2009).

- Uso do sistema plantio direto: a manutenção do solo estruturado e coberto com plantas vivas ou com palha é fator-chave para que o solo suporte a ação mecânica do pisoteio de animais, sem que haja compactação (Braida et al., 2006).

- Rotação de culturas: assim como em qualquer sistema de produção vegetal, a rotação de culturas é imprescindível para a sustentabilidade do sistema de ILP, pois melhora a qualidade e a conservação do solo, reduz a incidência de pragas, doenças e plantas daninhas, e aumenta a diversificação temporal da exploração econômica na propriedade rural (Balbinot Jr et al., 2009).

- Uso de vegetais e animais com melhor potencial genético que apresentem elevado rendimento com parâmetros qualitativos e de rusticidade desejados, sendo que um dos requisitos para que o sistema de ILP seja sustentável é a obtenção de rendimentos elevados (Balbinot Jr et al., 2009).
- Manejo correto da pastagem, principalmente em termos de adubação e altura da pastagem. 0 manejo apropriado da pastagem é fator imperativo para o sucesso do sistema de ILP (Cardoso et al., 2007). Em relação à adubação, o uso de nitrogênio $(\mathrm{N})$, além de aumentar o rendimento de forragem, pode melhorar o desempenho de culturas semeadas em sucessão, devido ao aproveitamento de $\mathrm{N}$ residual (Assmann et al., 2003). Além do N, tem sido comum pastagens com deficiência de fósforo e potássio. Quanto à altura da pastagem, cada espécie forrageira apresenta altura mais adequada de pastejo dependendo das suas características morfofisiológicas (Balbinot Jr et al., 2009).

Assmann et al. (2004) avaliaram o desempenho de novilhas da raça Charolês em sistema de ILP em consórcio de trevo branco com azevém, submetidas a doses de N, e observaram que o ganho de peso médio diário (GMD) não sofreu influência significativa das doses de $\mathrm{N}$. A não influência do $\mathrm{N}$ era esperada, uma vez que se procurou manter em todos os tratamentos a mesma oferta de forragem (14 $\mathrm{cm}$ de altura) para os animais. Ocorreu um aumento do ganho de peso vivo por área (GPA), que variou de 480 a $656 \mathrm{~kg} / \mathrm{ha}$ para o uso de uma adubação equivalente a 0 e $300 \mathrm{~kg} / \mathrm{ha}$ de $\mathrm{N}$, respectivamente. Os autores concluíram que o consórcio de gramíneas com leguminosa de estação fria possibilita o aumento do período de pastejo e, consequentemente, resulta em melhor desempenho animal no sistema de ILP.

Assmann etal. (2010) examinaram o desempenho de novilhos inteiros da raça Purunã em sistema de ILP em consórcio de trevo branco com aveia submetidos a doses de $\mathrm{N}$, e verificaram que as parcelas que receberam de $\mathrm{N}$ resultaram em maior GMD, que foi de $1,50 \mathrm{~kg} /$ animal/dia, enquanto que a aveia (controle) e aveia + trevo resultaram em ganhos de 1,06 e $1,13 \mathrm{~kg} / \mathrm{animal} /$ dia, respectivamente. Para o ganho de GPA total durante os 89 dias de pastejo, os valores foram de 541,49, 404,83 e 379,60 kg PV/ha para aveia $+\mathrm{N}$, aveia + trevo e aveia, respectivamente. Os autores concluíram que a inclusão de trevo branco em consórcio com aveia no sistema de ILP não é suficiente para manter a sustentabilidade de sistemas intensivos de elevada produtividade, onde os parâmetros ligados à produção animal são assegurados pelo uso da adubação nitrogenada. 


\section{Culturas e forrageiras utilizadas no sistema de integração lavoura-pecuária}

Dentre as culturas mais utilizadas nos sistemas de IPL destacam-se o arroz, feijão, fumo, milho e soja, dentre outras. De acordo com Garcia et al. (2004), dentre as forrageiras perenes mais utilizadas estão as espécies dos gêneros Brachiaria, Panicum, Cynodon e Andropogon. Quanto às forrageiras anuais de inverno, destacam-se o azevém, triticale, centeio e aveia, que são utilizadas nas regiões com inverno mais frio. Em relação às forrageiras anuais de verão, o sorgo e o milheto são bastante utilizados. Quanto às leguminosas, tem destaque o trevo, amendoimforrageiro, estilosante e a ervilhaca (Assmann et al., 2008).

Entre as diversas modalidades de IPL, a incorporação da gliricídia e da leucena em sistemas de ILP tem sido o foco principal dos trabalhos conduzidos nas áreas do semiárido. 0 cultivo da gliricídia em consórcio surge como nova opção para aumentar a sustentabilidade das pastagens. Nesse sistema a leguminosa funciona com um duplo propósito: melhoria da fertilidade do solo e complemento alimentar dos rebanhos. Durante o período das águas, ocorre normalmente uma baixa aceitação da gliricídia pelos animais, sendo a biomassa proveniente de folhas e ramos podada e deixada no solo para decomposição. Com o avanço da estação seca ocorre a diminuição da qualidade do capim e a gliricídia passa a ser um excelente complemento alimentar (Rangel et al., 2001). A leucena pode ser utilizada na produção de forragem, madeira, sombreamento, cerca viva e melhoramento do solo através de nódulos presentes nas raízes, capazes de transformar o fósforo inorgânico em orgânico, sendo este último útil para a utilização pelas plantas. Pode ser utilizada também como $\mathrm{N}$ disponível no solo, na quantidade de matéria orgânica e na capacidade de retenção de água no solo, diminuindo, assim, a evaporação e a erosão do solo (Kluthcouski, 1982).

$\mathrm{Na}$ escolha das espécies forrageiras utilizadas nos sistemas de ILP devem ser considerados alguns critérios importantes, tais como: adaptação edafoclimática, exigência nutricional, valor nutritivo, resistência ao pisoteio, persistência, produção de sementes, entre outros (Garcia et al., 2004).

\section{Alternativas de integração lavoura-pecuária}

A integração pode ser feita pelo consórcio, sucessão ou rotação das atividades agrícolas e pecuárias dentro da propriedade rural de forma planejada, constituindo um mesmo sistema, de tal maneira que há benefícios para ambas (Alvarenga et al., 2007).

\section{Consórcio de culturas anuais com forrageiras}

Pastagens degradadas em solo degradado podem ser recuperadas consorciando-se arroz com pastagens. A produção de grãos tem sido suficiente para amortizar, parcial ou totalmente, os gastos despendidos com a recuperação ou renovação das pastagens (Lustosa, 2007).

\section{Sucessão de culturas anuais por forrageiras anuais}

A sucessão de culturas anuais por forrageiras anuais tem sido utilizada quando o objetivo é produzir forragem para ensilagem ou pastejo, principalmente na entressafra. Esta alternativa contempla o plantio de cultura de verão, que pode ser a soja, seguida de cultivo de espécie forrageira anual, especialmente milheto ou sorgo para pastejo (Lustosa, 2007).

\section{Rotação de culturas anuais com forrageira}

Em áreas com pastagem e solo degradados também é possível estabelecer a rotação lavourapastagem, envolvendo principalmente as culturas de arroz e soja, desde que a área seja devidamente corrigida em relação à acidez do solo e à adubação (Kluthcouski et al., 2004).

\section{Integração em áreas com pastagem degradada}

Pastagem degradada pode ser recuperada pelo consórcio de culturas anuais, como milho ou sorgo com Brachiarias, e soja com Brachiarias. Após a 
colheita da cultura anual, a forrageira ainda terá chuva suficiente para o seu pleno estabelecimento e acúmulo forrageiro para o outono-inverno (Kluthcouski et al., 2004). Com o objetivo de restabelecer um bom índice de produtividade da pastagem, é possível adotar as modalidades de integração relacionadas abaixo (Lustosa, 2007).

\section{Rotação/sucessão de culturas anuais com forrageiras}

Recomenda-se que pastagens implantadas em solos ainda não degradados sejam recuperadas pela rotação com soja. 0 procedimento consiste em calagem do solo, se necessário, e semeadura direta da soja sobre a palhada da Brachiaria. Caso seja necessário manter a rotação por mais de um ano, para melhor condicionamento da fertilidade do solo, pode-se, a cada entressafra, plantar forrageiras anuais na área (Lustosa, 2007).

\section{Integração em áreas de lavoura com solo corrigido}

Em solos sob exploração de lavouras, as alternativas de integração visam principalmente a produção forrageira para a entressafra. Desta forma, o produtor poderá adotar as opções que se seguem, em função de seu interesse (Lustosa, 2007).

\section{Consórcio de culturas anuais com forrageiras}

No consórcio de culturas anuais com forrageiras, em áreas de produção de grãos das principais culturas anuais, são possíveis as associações de milho e sorgo, com Brachiaria e Panicum, e soja com Brachiaria (Lustosa, 2007).

\section{Sucessão de culturas anuais por forrageiras anuais}

A sucessão de culturas anuais com forrageira objetiva a produção de pastagens para a entressafra ou período seco. Consiste em semear, após a colheita da cultura de verão, forrageira anual como o sorgo pastejo ou o milheto (Lustosa, 2007).

Rotação de culturas anuais por forrageiras perenes

Esta alternativa de integração reúne todas as vantagens inerentes às explorações lavoureira e pecuária, tanto para a manutenção de altas produtividades nas pastagens quanto para a produção de grãos. Poderá ser plantado o milho ou a soja, rotacionados principalmente com forrageiras dos gêneros Brachiaria e Panicum (Kluthcouski et al., 2004).

\section{Benefícios da integração lavoura-pecuária}

Proporciona vantagens biológicas, ecológicas e econômicas em relação a sistemas de produção não integrados (Moraes et al., 2004; Russelle et al., 2007; Sulc e Tracy, 2007).

\section{As principais vantagens biológicas}

Elevada velocidade de ciclagem de nutrientes: os animais em pastejo representam agentes aceleradores da ciclagem de nutrientes. Grande parte dos nutrientes ingeridos retorna ao solo via fezes e urina, os quais são liberados à solução do solo em curto intervalo de tempo, estando disponíveis para nova absorção pelas raízes das plantas (Russelle et al., 2007).

\section{Melhoria da qualidade do solo}

O sistema IPL pode aumentar as concentrações de matéria orgânica no solo ao longo do tempo, devido ao crescimento contínuo de plantas na área, seja pastagem ou culturas para exploração vegetal, rotação de culturas, incremento da massa produzida por tempo em decorrência do pastejo e maior ciclagem de nutrientes (Tracy e Zhang, 2008). 0 teor de matéria orgânica é um atributo que pode servir de indicador de qualidade do solo (Singer e Ewing, 2000; Conceição et al., 2005), já que este afeta diretamente os atributos físicos, químicos e biológicos do solo.

\section{Benefícios ecológicos}

Redução da biota nociva às espécies cultivadas e consequente redução da necessidade de defensivos agrícolas, e redução da erosão (Kluthcouski et al., 2004). Diversificação de renda, resultante da produção vegetal e animal na mesma área (Fontaneli et al., 2000). Redução de riscos de insucesso econômico, já que há maior diversificação de atividades econômicas (Ambrosi et al., 2001). Maior geração de tributos e de empregos diretos 
e indiretos (Kluthcouski et al., 2004). Aumento da renda por área se comparado a sistemas não integrados (Fontaneli et al., 2000). Isso ocorre devido ao uso contínuo das áreas agrícolas, ao aumento de rendimento vegetal e/ou animal (Assmann et al., 2003; Moraes et al., 2004) e à redução de custos de produção ocasionados pelas vantagens biológicas.

Segundo Nascimento e Carvalho (2011), a integração oferece vantagens à pecuária, como o aproveitamento dos resíduos das adubações deixadas pelas lavouras, acarretando em produção de forragem de melhor qualidade, recuperação da produtividade de pastagens, aumento no ganho de peso dos animais e na produção de leite mesmo na época seca, em que as pastagens se encontram em pouca quantidade e com sua qualidade prejudicada.

\section{Rapidez e economicidade}

A ILP torna mais fácil a recuperação (manter a mesma espécie forrageira) ou a renovação (troca da espécie forrageira) da pastagem, pois o retorno do capital investido é mais rápido. Além disso, a formação da pastagem após a agricultura é rápida e se faz a custos menores. No caso de sucessão ou rotação com soja, a forrageira ainda pode se beneficiar dos mais de $100 \mathrm{~kg} / \mathrm{ha}$ de $\mathrm{N}$ fixados simbioticamente pela leguminosa.

Produção de forragem na época mais crítica do ano

Após a cultura anual de verão, pode-se semear as forrageiras anuais, como o milho, sorgo e milheto, e a aveia, nas regiões com inverno mais frio. Podese assim produzir alimentos para os bovinos tanto sob pastejo (aveia, milheto e sorgo para pastejo), feno (aveia e sorgo para pastejo) e silagem (sorgo forrageiro e milho). A experiência tem mostrado que forrageiras perenes, principalmente as braquiárias, são mais produtivas no primeiro ano após a implantação, inclusive permanecendo verdes durante a maior parte do período seco.

\section{Benefícios da pecuária para a lavoura}

\section{Rotação de Culturas}

De acordo com Kluthcouski et al. (2004), a ILP exige maior frequência de rotação de culturas anuais $\mathrm{x}$ forrageiras. Isto proporciona redução de inóculos de pragas e doenças, inclusive quebrando os seus ciclos, bem como o das plantas daninhas.

\section{Recuperação física, química e biológica do solo}

Abundância e agressividade das raízes das forrageiras tropicais, bem como a constante emissão de novas raízes, aliada à maior atividade biológica no solo, além de promoverem a reciclagem de nutrientes e a deposição de altas quantidades de matéria orgânica na superfície e no perfil do solo, favorecem a aração biológica do solo em profundidades que dificilmente seriam alcançadas por equipamentos convencionais.

Melhoramento da estrutura do solo, devido, principalmente, à matéria orgânica e exsudados das raízes, resultando numa melhor porosidade do solo, armazenamento de água e crescimento das raízes das culturas anuais. Cobertura do solo: as espécies forrageiras, além da produção forrageira para os animais, servem de fonte de cobertura do solo para o Sistema Plantio Direto de culturas anuais. A palhada proveniente das forrageiras garante quantidade suficiente para a proteção de toda a superfície do solo, desde que devidamente manejadas, e podem, além de reduzir a evaporação da água no solo, dificultar a emergência de plantas daninhas e o ataque de fungos do solo sobre as plantas cultivadas. Dentre as desvantagens do sistema de ILP, pode-se relacionar a possibilidade de ocorrência de compactação superficial do solo, em situação de manejo inadequado da pastagem (Balbinot Jr et al., 2009).

\section{Sistemas de integração lavoura-pecuária}

\section{Sistema Barreirão}

O Sistema Barreirão foi desenvolvido pela Embrapa e consiste em plantar uma cultura anual (soja, milho, arroz) consorciada com uma forrageira para pastejo, principalmente a Brachiaria decumbens ou Brachiaria brizantha (Zanine et al., 2006). Segundo Cobucci et al. (2007), o Sistema Barreirão tem como objetivo principal a recuperação/renovação de pastagens degradadas 
e a redução dos custos na formação de novas áreas. Neste sistema é feito normalmente lavoura de quatro em quatro anos para a recuperação das pastagens. 0 maior benefício do Sistema Barreirão se dá, em um primeiro momento, com o incentivo aos produtores para a necessidade de se recuperar/ renovar pastagens degradadas e, posteriormente, com as vantagens da ILP.

\section{Sistema Santa Fé}

O Sistema Santa Fé também foi desenvolvido pela Embrapa e fundamenta-se na produção consorciada de culturas de grãos, especialmente o milho, sorgo, milheto, arroz, soja e girassol com forrageiras tropicais, principalmente as do gênero Brachiaria, tanto no sistema de plantio direto como no convencional, em áreas de lavoura com solo devidamente corrigido. O consórcio é estabelecido anualmente, podendo ser implantado simultaneamente ao plantio da cultura anual ou cerca de 20 a 30 dias após a sua emergência. As culturas anuais apresentam grande performance de desenvolvimento inicial, exercendo alta competição sobre as forrageiras e evitando, assim, redução significativa nas suas capacidades produtivas de grãos. Este sistema apresenta grande vantagem, pois não altera o cronograma de atividades do produtor e não exige equipamentos especiais para sua implantação (Kluthcouski et al., 2000).

Segundo Kluthcouski et al. (2000), este sistema teve início com o objetivo de ensilagem ou corte da Brachiaria brizantha para fornecimento no cocho para animais confinados. No Sistema Santa Fé, a lotação de animais deve ser alta para não permitir que a forrageira sementeie no inverno, sendo indicado para propriedades que fazem apenas uma lavoura de verão por ano e deixam a área ociosa no inverno.

\section{Manejo das pastagens no sistema de integração lavoura-pecuária}

Manejar osanimais no sistema deILP compreende levá-los para áreas onde haja forrageiras em condições de alta oferta, onde o solo não seja sacrificado e os animais possam se alimentar sem dificuldades e proporcionar resposta em produção de carne e de leite (Soares, 2008). A manutenção da altura da pastagem, independentemente do sistema utilizado, é recomendada para cada espécie, sendo importante para obtenção de alto rendimento e qualidade forrageira e, ao mesmo tempo, melhoria da qualidade do solo e redução de compactação imposta pelo pisoteio. Além disso, pastagens que apresentam baixa cobertura do solo devido ao pastejo excessivo permitem infestações de plantas daninhas e ocorrência de erosão hídrica (Balbinot Jr et al., 2009). Resultados de pesquisa demonstraram que o manejo correto das pastagens é determinante para a manutenção de um bom sistema de ILP. Em termos de manejo de pastejo, o produtor/ técnico tem em mãos três ferramentas passíveis de manipulação: tempo de pastejo, tempo de descanso e intensidade de pastejo (Soares, 2008).

\section{Pastejo contínuo}

Preconiza-se o pastejo contínuo com lotação variável, ou seja, deve-se reduzir ou aumentar o número de animais sobre a área quando ocorre redução ou aumento da oferta de forragem e nos períodos de maiores precipitações pluviométricas, que podem prejudicar o solo e as plantas através de pisoteio intenso. Este método pode ser monitorado pela altura da pastagem, o que varia de acordo com a espécie. As alturas devem atender à necessidade dos animais, permitindo ganho de peso e produção de leite. Por outro lado, a forragem deve ter uma garantia de área foliar suficiente para interceptar a radiação solar, continuar a rebrota e perfilhar. No final, com a dessecação, fornecerá cobertura vegetal satisfatória do solo para a semeadura das culturas de verão (Soares, 2008).

\section{Pastejo intermitente}

Este método de pastejo é bastante difundido e caracteriza-se pela divisão da área de pastagem em parcelas menores ou piquetes fixos, onde os animais entram quando o volume de forragem é suficiente e são retirados quando a quantidade de forragem atinge um limite inferior, geralmente estabelecido pela altura para cada espécie. Em seguida, os animais são transferidos para o próximo piquete, 
ainda não pastejado, dessa maneira passando de piquete em piquete até retornarem ao primeiro, quando este apresentar novamente condições de pastejo. Tal sistema de manejo permite um melhor aproveitamento da pastagem, porém diminui a seletividade dos animais em pastejo, fazendo com que a produção individual dos animais seja diminuída; entretanto, a produção animal por hectare aumenta $12 \%$ em média. São necessários cuidados durante este método para evitar a compactação do solo e consequentes prejuízos na produção das culturas de verão como milho, feijão e soja. Este método é mais recomendado para pastagens perenes de verão, especialmente as forrageiras (Soares, 2008).

\section{Pastejo contínuo em faixas}

Este método de pastejo utiliza cercas móveis que são deslocadas de acordo com o tempo que se quer disponibilizar o pasto aos animais, podendo variar desde algumas horas até um, dois ou três dias. Assim como na lotação intermitente, a contínua em faixas permite controlar o momento da entrada e da saída, baseados na oferta de forragem, porém não permite seletividade aos animais e pode compactar o solo pelos motivos já expostos anteriormente. Recomenda-se disponibilizar bebedouros para os animais durante o período de pastejo, aproveitando mais a forrageira disponível e manejando as cercas elétricas móveis de acordo com as faixas de consumo de forragem (Soares, 2008).

\section{Efeitos da integração lavoura-pecuária na produção animal}

A principal fonte de alimentação para os bovinos na região tropical são as pastagens que, no entanto, encontram-se em processo de degradação devido à má formação do pasto, manejo inadequado sem reposição de nutrientes, falta no controle da taxa de lotação e no gerenciamento da propriedade. Em média, o rebanho bovino brasileiro apresenta desempenho muito baixo, com uma produtividade média em torno de 3,29 arrobas (@) por hectare por ano (Barbosa et al., 2015). Com o sistema de ILP, as pastagens aproveitam os resíduos de nutrientes deixados pela lavoura, aumentando a fitomassa vegetal e proporcionando aumentos de produtividade de forragem.

De acordo com Salton et al. (2002), a produtividade de grãos e de carne e leite obtida nos sistemas integrados de lavoura-pecuária é variável, pois depende de vários fatores: sistema de produção, clima, tempo de implantação, manejo das pastagens, entre outros. Nesses sistemas integrados deve ser priorizada a criação de animais com potencial genético e ajustada a lotação com base na oferta de forragem, otimizando todos os componentes do manejo da pastagem, pois as pastagens estabelecidas apresentam produção e qualidade elevadas.

Em relação à produção animal obtida em sistema de ILP, deve-se considerar o uso de pastagens perenes. Nesse caso, as pastagens podem se beneficiar de adubações residuais de culturas anuais e, consequentemente, exibir alta produção forrageira, que pode ser convertida em carne ou leite (Kluthcouski et al., 2003).

Aguinaga et al. (2006) avaliaram o desempenho de novilhos mestiços mantidos em pastagem consorciada de aveia preta com azevém, manejada com diferentes alturas em sistema de ILP, e relataram que o aumento no GMD foi condicionado pelo incremento na quantidade de forragem disponível até a altura de $40 \mathrm{~cm}$. Os valores de GPA apresentaram respostas lineares e negativas, ou seja, à medida que aumentou a altura de manejo da pastagem, o GPA reduziu. Os autores concluíram que o desempenho individual de novilhos de corte em pastagens de aveia + azevém é otimizado com o aumento da altura de manejo até valores próximos a $40 \mathrm{~cm}$, e para o ganho por área, uma faixa de valor ótimo de manejo da pastagem seria em torno de $25 \mathrm{~cm}$ de altura.

Lopes et al. (2008) analisaram o desempenho de novilhos mestiços terminados em pastagem consorciada de aveia preta com azevém em sistema de ILP e manejadas com diferentes alturas, e verificaram que à medida que foram aumentadas as alturas de pastejo, houve incremento no desempenho individual até a altura $25 \mathrm{~cm}$, com GMD estimado de 1,225 kg/animal/dia. Em alturas do pasto entre 20 e $30 \mathrm{~cm}$, a curva de resposta estima valores de desempenho superiores a 1,0 
$\mathrm{kg} / \mathrm{animal} / \mathrm{dia}$, o que representa uma velocidade de ganho de peso interessante para o propósito da terminação dos novilhos em condições adequadas ao final do ciclo da pastagem de inverno. Quanto ao GPA, houve uma resposta linear negativa, sendo que à medida que foi aumentada a altura de manejo do pasto, o GPA decresceu. Em relação ao GPA, em se tratando de um sistema de ILP, o elevado nível de produção obtido no tratamento de $10 \mathrm{~cm}$ de altura deve ser analisado com cautela para não ocasionar alterações no solo. Os autores concluíram que o desempenho individual de novilhos de corte superprecoces em pastagem de aveia e azevém é otimizado com o aumento da altura do pasto até valores entre 25 e $30 \mathrm{~cm}$, com ganho de peso por animal superior a $1,0 \mathrm{~kg} /$ dia, e que a produção de peso vivo por hectare aumenta linearmente com a redução da altura de pastejo até $10 \mathrm{~cm}$.

Turini (2009) mensurou o desempenho de bovinos de corte Angus x Nelore, inteiros e castrados em sistema de ILP em consórcio de pasto perene de verão com grama estrela roxa e capim mombaça, e pastagem anual de inverno com aveia e azevém. Em relação ao GMD, os animais inteiros apresentaram valores maiores do que os castrados. O GMD do período de inverno foi superior ao do verão, o que pode ser explicado em função da diferença no tipo de gramínea ofertada, da diferente qualidade entre as forragens nos dois períodos distintos e da fase de crescimento em que os animais se encontravam. Durante o período de inverno, os animais alimentavam-se com aveia e azevém e apresentavam-se na fase inicial de recria. No período de verão, os animais ingeriam grama estrela roxa e capim mombaça, e encontravam-se na fase final de recria e fase de terminação ou engorda. Os animais não apresentaram grandes perdas de peso ou queda no desempenho, resultado da oferta constante de alimento durante todo o ano, objetivo do sistema de ILP. Assim, os bovinos puderam ser abatidos mais precocemente: os inteiros com 19,1 meses e os castrados com 20,7 meses. Os autores concluíram que a utilização de animais inteiros ou castrados, em sistema de ILP, influenciou o desempenho dos animais.

Silva et al. (2011) avaliaram o desempenho de novilhas leiteiras com duas categorias, leves e pesadas, em pastagem consorciada composta por azevém, aveia preta, trevo branco e vermelho e pastagem pura de azevém, e observaram que as novilhas leves apresentaram maior GPA em pastagem pura de azevém $(3,85 \mathrm{~kg} / \mathrm{ha} / \mathrm{dia})$, enquanto as novilhas pesadas tiveram maior GPA em pastagem consorciada (3,34 kg/ha/dia). As novilhas mantidas em pastagem pura de azevém apresentaram GMD superior $(0,93 \mathrm{~kg} / \mathrm{dia})$ ao das novilhas mantidas em pastagem consorciada $(0,79 \mathrm{~kg} / \mathrm{dia})$. Os autores concluíram que o desempenho por unidade de área depende da categoria animal, sendo que novilhas leves têm melhor desempenho em pastagens puras de azevém, enquanto novilhas pesadas têm melhor desempenho em pastagens consorciadas.

Vilela et al. (2011), trabalhando com sistema de ILP no processo de intensificação de uso das áreas em exploração com lavoura de grãos e pastagens, descreveram os resultados de ganho de peso animal em experimento de longa duração da Embrapa Gado de Corte, onde estão sendo testados diferentes sistemas tradicionais e de ILP, e observaram que nos sistemas de rotação lavoura-pasto (L4-P4 e L1-P3) os animais apresentaram maiores ganho de peso, $495 \mathrm{e}$ $518 \mathrm{~kg} / \mathrm{ha}$, respectivamente, e a pastagem degradada obteve o menor ganho de peso, com $141 \mathrm{~kg} / \mathrm{ha}$.

Siqueira Jr (2005) mediu a produção de leite de vacas da raça Holandesa e Jersey em sistema de ILP, mantidas em pastagem consorciada de aveia preta com azevém e suplementadas com $0,33,66$ e 100\% da dieta (silagem de milho + concentrado), que atendia as exigências de mantença e produção de 28 litros de leite/dia, e observou que houve diferença significativa entre as médias de produção de leite com maiores valores para as vacas que receberam 66 e 100\% de suplementação, com 38,77 e 41,40 litros/vaca/dia, respectivamente.

Silva (2005) examinou a produção de leite de vacas da raça Holandesa e Jersey em sistema de ILP, mantidas em pastagem anual de inverno consorciada de aveia preta com azevém e suplementadas com $0,33,66$ e $100 \%$ da dieta (silagem de milho + concentrado), que atendia as exigências de mantença e produção de 28 litros de leite/dia. As vacas permaneceram por três meses na pastagem de inverno e foram, então, transferidas para a pastagem de verão, constituída de capim quicuio e milheto. 0 autor relatou que no período de inverno houve diferença significativa entre as produções 
médias de leite das vacas que não receberam suplementação e das que receberam 100\%, apresentando produções de 16,45 e 25,00 litros/ vaca/dia, respectivamente. Já a produção de leite das vacas que receberam 33 e $66 \%$ da suplementação, 19,93 e 23,41 litros/vaca/dia, respectivamente, não diferiu das produções das vacas que não receberam. Quanto ao período de verão, houve redução na produção de leite, com menores valores para as vacas que não receberam suplementação e que receberam $33 \%$ de suplementação com 12,47 e 15,93 litros/ vaca/dia, respectivamente.

Souto (2006) avaliou a produção de leite de vacas da raça Holandesa e Jersey em sistema de ILP, mantidas em pastagem consorciada de aveia preta com azevém e suplementadas com 20, 45, 65 e $100 \%$ da dieta (silagem de milho + concentrado), que atendia as exigências de mantença e produção de 28 litros de leite/dia. 0 autor relatou que em pastagem consorciada e com suplementação de apenas $20 \%$, a produção foi de 20,68 litros/vaca/ dia e não diferiu daquela em que se utilizou $100 \%$ de suplementação, que foi de 23,06 litros/vaca/ dia; as produções médias foram referentes aos três períodos de avaliação. Isso demonstrou a oportunidade de produção de leite em pastagens anuais de inverno, cultivadas em sistema de ILP, e concluiu que a maior participação da pastagem de aveia/azevém na alimentação das vacas permite a manutenção da produção leiteira.

Silva et al. (2008) mensuraram a produção de leite de vacas da raça Holandesa e Jersey em sistema de ILP, mantidas em pastagem anual de inverno consorciada de aveia preta com azevém e suplementadas com 20,45, 65 e $100 \%$ da dieta (silagem de milho + concentrado) que atendia as exigências de mantença e produção de 28 litros de leite/dia. As vacas permaneceram por três meses na pastagem de inverno e foram, então, transferidas para a pastagem de verão, constituída de capim quicuio. Os autores verificaram que no período de inverno não houve diferença significativa entre as médias de produção de leite, com valores que variaram de 22,02 a 24,49 litros/vaca/dia. Já no período de verão, houve redução na produção de leite, com menores valores para as vacas que receberam 20 e $45 \%$ da suplementação $(15,92$ e 17,85 litros/vaca/dia), e concluíram que é possível obter produções de forragens de boa qualidade de pastagens anuais de inverno, de verão e perenes de verão, suficientes para garantir a produção de leite de maneira sustentável durante o ano todo, de forma integrada à produção de grãos, no sistema de ILP.

Costa (2017) averiguou o desempenho de bovinos cruzados, sendo AN ( $1 / 2$ Angus $\times 1 / 2$ Nelore) e CAN $(1 / 2$ Charolês $\times 1 / 4 \times$ Angus $\times 1 / 4$ Nelore) recriados em sistema de ILP e terminados em confinamento. Os animais foram recriados em pastagem oriunda de um ILP, recebendo suplementação (suplemento proteico na seca e suplemento mineral nas águas). No período das águas, os animais AN apresentaram desempenho superior aos animais CAN, com GMD de 0,748 kg e $0,490 \mathrm{~kg}$, respectivamente. A produtividade na recria no sistema de ILP foi de $926 \mathrm{~kg} /$ ha de peso corporal no período de 11 meses.

Ruviaro et al. (2016), estudando a viabilidade econômica e ambiental da produção de carne em diferentes sistemas alimentares no bioma Pampa, constataram melhores resultados nos sistemas de produção utilizando pastagem nativa com suplementação proteica e energética e sistema integrado de pastagem nativa com azevém. Com os resultados verificados é possível concluir que a produção de carne aumenta sem a necessidade de novas áreas de gado e contribui para o uso adequado e preservação do bioma de Pampa. Martha Jr et al. (2011) analisaram economicamente a pecuária de corte em sistema extensivo e em ILP, e encontraram produtividade média anual da pecuária na ILP de 17,9@/ha/ano, e de 7@/ha/ano no sistema extensivo, demostrando aumento da produtividade e de renda no sistema de ILP.

As pastagens em sistemas de ILP apresentam características mais favoráveis do que as pastagens convencionais para a nutrição de bovinos, sendo a maior disponibilidade de matéria seca e melhor valor nutricional da forragem ingerida (Almeida e Medeiros, 2015).

\section{Conclusão}

O sistema de integração lavoura-pecuária tem potencial para aumentar a produtividade de grãos, carne e/ou leite, e reduzir os efeitos da degradação das pastagens de forma sustentável. No entanto, para 
o adequado funcionamento, alguns fundamentos devem ser atendidos, além da sincronização correta entre o uso dos principais componentes do sistema, o solo, a planta e o animal.

\section{Referências}

Abreu Jr CH, Muraoka T, Lavorante AF. Relationship between acidity and chemical properties of Brazilian soils. Sci Agric (Piracicaba, Braz). 2003;60(2):337-43.

Agnes EL, Freitas FCL, Ferreira LR. Situação atual da integração agricultura-pecuária em Minas Gerais e na Zona da Mata Mineira. In: Zambolin L, Ferreira AA, Agnes EL (EE). Manejo integrado: integração agriculturapecuária. Viçosa: Universidade Federal de Viçosa; 2004. p. 251-67.

Aguinaga AAQ, Carvalho PCF, Anghinoni I, Santos DT, Freitas FK, Lopes MT. Produção de novilhos superprecoces em pastagem de aveia e azevém submetida a diferentes alturas de manejo. R Bras Zootec. 2006;35(4):1765-73.

Almeida RG, Medeiros SR. Emissão de gases de efeito estufa em sistemas de integração lavoura-pecuáriafloresta. In: Alves FV, Laura VA, Almeida RG (EE). Sistemas agroflorestais - a agropecuária sustentável. Brasília: Embrapa e Serviço Nacional de Aprendizagem Rural (Senar); 2015.

Alvarenga RC, Gontijo Neto MM, Ramalho JH, Garcia JC, Viana MCM, Castro AADN. Sistema de integração lavourapecuária: o modelo implantado na Embrapa milho e sorgo. Circular Técnica, 93. Sete Lagoas: Embrapa Milho e Sorgo; 2007.9 p.

Ambrosi I, Santos HP, Fontaneli RS, Zoldan SM. Lucratividade e risco de sistemas de produção de grãos combinados com pastagens de inverno. Pesq Agropec Bras. 2001;36(10):1213-9.

Assmann TS, Rondelli Jr TP, Moraes A, Assmann AL, Koehler HS, Sandini, I. Rendimento de milho em área de integração lavoura-pecuária sob o sistema plantio direto, em presença e ausência de trevo branco, pastejo e nitrogênio. Rev Bras Ciênc Solo. 2003;27(4):675-83.
Assmann AL, Pelissari A, Moraes A, Assmann TS, Oliveira EB, Sandini I. Produção de gado de corte e acúmulo de matéria seca em sistema de integração lavoura-pecuária em presença e ausência de trevo branco e nitrogênio. $\mathrm{R}$ Bras Zootec. 2004;33(1):37-44.

Assmann AL, Silva HL, Kirchner R, Kozelinski SM. Espécies forrageiras para o sistema integração lavoura-pecuária. In: Assmann AL, Soares AB, Assmann TS (EE). Londrina: IAPAR; 2008. $49 \mathrm{p}$.

Assmann TS, Assmann AL, Assmann JM, Soares AB, Bortolli MA. Produção de gado de corte e de pastagem de aveia em sistema de integração lavoura-pecuária em presença e ausência de trevo e nitrogênio. R Bras Zootec . 2010;39(7):1387-97.

Balbinot Jr AA, Veiga AMM, Pelissari A, Dieckowiv J. Integração lavoura-pecuária: intensificação de uso de áreas agrícolas. Cienc Rural. 2009;39(6):1925-33.

Barbosa FA, Soares Filho BS, Merry FD, Azevedo HO, Costa WLS, Coe MT, et al. Cenários para a Pecuária de Corte Amazônica. Belo Horizonte: IGC/UFMG; 2015. 146 p.

Borges EP. História do processo integração agriculturapecuária. In: Zambolim L, Silva AA, Agnes EL (EE). Manejo da Integração Agricultura-Pecuária. Viçosa: Universidade Federal de Viçosa; 2004. p. 353-84.

Braida JA, Reichert JM, Veiga M, Reinert DJ. Resíduos vegetais na superfície e carbono orgânico do solo e suas relações com a densidade máxima obtida no ensaio proctor. Rev Bras Ciênc Solo. 2006;30(4):605-14.

Cardoso RR, Carvalho PCF, Carassai IJ, Flores JPC, Nabinger C, Freitas FK, et al. O manejo do pastejo e seu impacto nos atributos físicos de um Argissolo Vermelho em integração lavoura-pecuária [CD-ROM]. Simpósio Internacional em Integração Lavoura-Pecuária; 13-15 ago 2007; Curitiba. Curitiba: Universidade Federal do Paraná; 2007.

Cassol LC. Relações solo-planta-animal num sistema de integração lavoura pecuária em semeadura direta com calcário na superfície [tese]. Porto Alegre: Universidade Federal do Rio Grande do Sul; 2003. 
Cobucci T, Kluthcouski J, Aidar H. Sistema Santa Fé: produção de forragem na entressafra. Workshop Internacional Programa de Integração Agricultura e Pecuária para o Desenvolvimento Sustentável das Savanas Tropicais Sulamericanas;12 - 13 jul 2001; Santo Antônio de Goiás. Santo Antônio de Goiás: Embrapa Arroz e Feijão; 2001. p. 125-35.

Cobucci T, Wruch FJ, Kluthcouski J, Muniz LC, Martha Jr GB, Carnevalli RA, et al. Opções de integração lavoura pecuária e alguns de seus aspectos econômicos. Informe Agropecuário. 2007;28(240):25-42.

Conceição PC, Amado TCA, Mielniczuk J, Spagnollo E. Qualidade do solo em sistemas de manejo avaliada pela dinâmica da matéria orgânica e atributos relacionados. Rev Bras Ciênc Solo. 2005;29(5):777-88.

Costa PM. Desempenho produtivo de bovinos cruzados em sistema de Integração Lavoura Pecuária [tese].Belo Horizonte: Universidade Federal de Minas Gerais; 2017.

Embrapa. Rio+20: recuperação de pastagens degradadas é tema de palestra no Píer Mauá. 2012 [acesso 1 nov 2017]. Disponível em: https://tinyurl.com/ycvla86v.

Fontaneli RS, Ambrosi I, Santos HP, Ignaczak JC, Zoldan SM. Análise econômica de sistemas de produção de grãos com pastagens anuais de inverno, em sistema plantio direto. Pesq Agropec Bras. 2000;35(11):2129-37.

Gimenes MJ, Dal Pogetto MHFA, Prado EP, Christovam RS, Souza EFC. Integração lavoura-pecuária: breve revisão. R Trop Ci Agr Biol. 2010;4(1):52-9.

Kluthcouski J, Stone LF, Aidar H (EE). Integração lavourapecuária. Santo Antonio de Goiás: Embrapa Arroz e Feijão; 2003. 570 p.

Kluthcouski J. Leucena: alternativa para a pequena e média agricultura. $2^{\circ}$ ed. Circular Técnica, 6. Brasília: Embrapa Arroz e Feijão; 1982.

Kluthcouski J, Aidar H, Stone LF, Cobucci T. Integração lavoura-pecuária e o manejo de plantas daninhas. Encarte Técnico, 106. Santo Antonio de Goiás: Embrapa Arroz e Feijão; 2004. p. 1-20.
Kluthcouski J, Cobucci T, Aidar H, Yokoyama LP, Oliveira IP, Costa JLS, et al. Sistema Santa Fé - Tecnologia Embrapa: integração lavoura-pecuária pelo consórcio de culturas anuais com forrageiras, em áreas de lavoura, nos sistemas direto e convencional. Santo Antônio de Goiás: Embrapa Arroz e Feijão; 2000.

Lopes MLT, Carvalho PCF, Anghinoni I, Santos TD, Kuss F, Freitas FK, et al. Sistema de integração lavoura-pecuária: desempenho e qualidade da carcaça de novilhos superprecoces terminados em pastagem de aveia e azevém manejada sob diferentes alturas. Cienc Rural. 2008;38(1):178-84.

Martha Jr GB, Alves E, Contini E. Dimensão econômica de sistemas de integração lavoura-pecuária. Pesq Agropec Bras. 2011;46(10):1117-26.

Mello LMM, Yano EH, Narimatsu KCP, Takahashi CM, Borghi E. Integração agricultura-pecuária em plantio direto: produção de forragem e resíduo de palha após pastejo. Eng Agric. 2004;24(1):121-9.

Moraes A, Lang CR, Pelissari A, Carvalho PCF. Integração agropecuária em sistema plantio direto: integração lavoura-pecuária no sul do Brasil. $9^{\circ}$ Encontro Nacional de Plantio Direto na Palha; 29 jun - 2 jul 2004; Chapecó. Ponta Grossa: Federação Brasileira de Plantio Direto na Palha; 2004. p. 19-22.

Nascimento RS, Carvalho NL. Integração lavourapecuária. Rev Monogr Ambient. 2011;4(4):828-47.

Pereira JC. As pastagens no contexto dos sistemas de produção de bovinos. In: Zambolim L, Silva AA, Agnes EL (EE). Manejo integrado: integração agricultura-pecuária. Viçosa: Universidade Federal de Viçosa; 2004. p.287-330.

Russelle MP, Entz MH, Franzluebberss AJ. Reconsidering integrated crop-livestock systems in North America. Agron J. 2007;99:325-34.

Ruviaro CF, Costa JS, Florindo TJ, Rodrigues W, Medeiros GIB, Vasconcelos PS. Economic and environmental feasibility of beef production in different feed management systems in the Pampa biome, southern Brazil. Ecol Indic. 2016;60:930-9. 
Salton JC, Fabrício AC, Machado LAZ. Integração lavourapecuária no sistema plantio direto. III Simpósio de Produção de Gado de Corte; 30 mai - 01 jun 2002; Viçosa, MG. Viçosa: Universidade Federal de Viçosa; 2002. p. 89-98.

Salton JC, Fabrício AM, Hernani LC. Integração lavourapecuária: alternativas de rotação de culturas. $5^{\circ}$ Encontro Regional de Plantio Direto no Cerrado; 2001; 9-13 jul 2001; Dourados. Brasília: APDC; Dourados: UFMS/ Embrapa Agropecuária Oeste; 2001. p. 31-2.

Silva HA. Análise de viabilidade da produção de leite a pasto e com suplementos em áreas de integração lavourapecuária na região dos Campos Gerais [dissertação]. Curitiba: Universidade Federal do Paraná; 2005.

Silva HA, Moraes A, Carvalho PCF, Pontes LS. Desempenho de novilhas leiteiras em pastagens anuais de inverno sob sistema de integração lavoura-pecuária. Pesq Agropec Bras. 2011;46(10):1372-8.

Silva HA, Koehler HS, Moraes A, Guimarães VA, Hack E, et al. Análise da viabilidade econômica da produção de leite a pasto e com suplementos na região dos Campos Gerais - Paraná. Cienc Rural. 2008;38(2):445-50.

Singer MJ, Ewing S. Soil quality. In: Sumner ME (E). Handbook of soil science. Boca Raton: CRC; 2000. p.G271-98.

Siqueira Jr LA. Alterações de características do solo na implantação de um sistema de integração agriculturapecuária leiteira [dissertação]. Curitiba: Universidade Federal do Paraná; 2005.

Soares AB, Assmann AL, Kirchner R, Assmann TS. Manejo das pastagens no sistema integração lavoura-pecuária. In: Assmann AL, Soares BA, Assmann TS (EE). Integração lavoura-pecuária para a agricultura familiar. Londrina: IAPAR; 2008. p. 38-49.

Souto MS. Pastagem de aveia e azevém na integração lavoura-pecuária:produção de leite e características do solo [dissertação]. Curitiba: Universidade Federal do Paraná; 2006.

Sulc RM, Tracy BF. Integrated crop-livestock systems in the U.S. corn belt. Agron J. 2007;99:335-45.
Tracy BF, Zhang Y. Soil compaction, corn yield response and soil nutrient pool dynamics within an integrated croplivestock system in Illinois. Crop Sci. 2008;48:1211-8.

Turini T. Desempenho de bovinos inteiros e castrados em sistema intensivo de integração lavoura - pecuária [dissertação]. Londrina: Universidade Estadual de Londrina; 2009.

Vilela L, Martha Jr GB, Macedo MCM, Marchão RL, Guimarães Jr R, Pulrolnik K, et al. Sistemas de integração lavoura-pecuária na região do Cerrado. Pesq Agropec Bras. 2011;46(10):1127-38.

Zanine AM, Santos EM, Ferreira DJ, Carvalho GGP. Potencialidade da integração lavoura- pecuária: relação planta-animal. Rev Electron Vet. 2006;7(1):1-23. 